\title{
Thinking in Complexity: A New Paradigm for Learning
}

\author{
A Response to Ton Jörg's Programmatic View
}

\author{
KLAUS MAINZER \\ Carl von Linde-Academy, Technical University of Munich (Germany)
}

The theory of complex dynamical systems is an interdisciplinary methodology to model nonlinear processes in nature and society. In the age of globalization, it is the answer to increasing complexity and sensitivity of human life and civilization (e.g., life science, environment and climate, globalization, information flood) (Mainzer 2007). Complex systems consist of many microscopic elements (molecules, cells, organisms) interacting in nonlinear manner and generating macroscopic order. Self-organization means the emergence of macroscopic states by the nonlinear interactions of microscopic elements. Chaos and randomness, growth and innovations are examples of macroscopic states modelled by phase transitions in critical states. The models aim at explaining and forecasting their dynamics (Mainzer 2008). In the case of randomness and chaos, there are restrictions to compute the macrodynamics of complex systems, even if we know all the laws and conditions of their local activities. The future cannot be forecast in the long run, but dynamical trends (e.g., order parameters) can be recognized and influenced ("bounded rationality"). Besides the methodology of mathematical and computerassisted models, there are practical and ethical consequences. For example: Be sensible to critical equilibria in nature and society (butterfly effect). Find the balance between selforganization, control, and governance of complex systems in order to support a sustainable future of mankind. 
What does that mean for learning and education? Ton Jörg offers a remarkable programmatic view. He demands learning as "bootstrapping" with concomitant effects on the partners in interaction. "Thinking in Complexity" has its focus on "that which is interwoven". Teaching is also considered invention. Whilst aware of the historical processes of inventing, we may open the vistas of reinventing the field of learning and teaching. To enable such a reinvention, we need to stop thinking linearly, which is quite dangerous in a nonlinear complex reality. This argument, as shown in my book, Thinking in Complexity (2007), is that most cognitive scientists seem to be unable to recognize and to explain emergent behavior as resulting from the causal dynamics of nonlinear interaction between the various components of social systems. Cross-catalytic and autocatalytic reactions of complex educational systems may be regarded as fundamentally transdisciplinary. With respect to the debate on "new learning" in the Netherlands, learning should become more personal, self-regulated, self-directed, and self-organized. However, an adequate theory of learning through social interaction, of how to make use of personal reciprocal relationships, is still lacking. Ton Jörg explains that "Thinking in Complexity" opens new avenues in education: of "learners who bootstrap each other" in sub-communities of mutual learners (yet?) to be created.

These arguments sound wonderful for me in two ways. As a complexity researcher I know the theoretical background of his arguments. As a father of four children I also know the praxis of education, at least in Germany, which fails in many respects. The educational programs often consist of "linearly separated and added" training blocks of standard knowledge. There is no room for personal motivation, self-organization or emergence of creative ideas, because there is not sufficient interaction, a necessary condition of the emergence of novelties in complex systems. The isolated training blocks are sometimes badly connected. Interdisciplinary correlations and mutual motivations of problem-oriented and correlated learning in different disciplines seem to be impossible. The pupils and students primarily have to realize a meaningful network of all the learnt and isolated facts in their own mind without any support and hint on self-organized learning and understanding. But creative learning means learning of learning and is definitely the decisive condition of inventions and innovations in modern societies. In the age of globalization, economic growth and the welfare of nations decisively depend on basic innovations. Therefore, education and knowledge is an advantage of competition in highly developed countries of Europe with high standards of salaries, but raw material shortage. The European Union (EU) tries to concentrate educational potentials in order to be successful in the global competition of educational markets. Therefore, Europe is on its way to a European university.

Which educational consequences can be concluded from these insights of complexity research in the nonlinear dynamics of globalization? The Technical University of Munich (TUM) can be considered a practical example on the background of global innovation dynamics and education. TUM has a great tradition since the 19th century and is today one of Germany's few universities which was distinguished by the government as a "university of excellence". TUM unifies a variety of disciplines in faculties of mathematics, physics, chemistry, civil engineering and surveying, 
architecture, mechanical engineering, electrical engineering and information technology, informatics, life and environmental science, medicine, sports science, and economics. TUM is considered an innovation enterprise with a distinguished combination of natural science, medicine, and life sciences. Further, interdisciplinary platforms, research projects, and courses of study have been created across all faculties. According to international elite-universities, TUM is embedded in a network of local centers of enterprise. Globally, strategic partnerships with other universities intensify exchange in teaching and research. The integration of industrial global players creates resources for international activities.

The Carl von Linde-Academy is an answer to the cultural and educational challenge in the age of complex globalization. Highly specialized knowledge is not sufficient in a complex world. Interdisciplinary and intercultural thinking is the strategic condition, in order to decide and act with responsibility. We need a variety of skills generated by the complex human mind and the correlated nonlinear dynamics of human brain. Therefore, the Carl von Linde-Academy offers a transdisciplinary education in humanities and social sciences supplementing the faculties and disciplines at TUM - in the old European tradition of humanism since the Athens' Academy. The foundation of the Carl von Linde-Academy was strongly supported by officials of state, economy, and society. For example, the Chief Executive Officer of a leading chemical industrial group proclaimed: "The increasing specialization of science needs a problem oriented supplement, in order to train alternative thinking and enable students to see their expert knowledge in the context of society."

The Academy aims at opening minds for scientific cultures, promoting the transfer of knowledge and skills from other disciplines, strengthening the sense of responsibility. The head of the Carl von Linde-Academy is the academic director assisted by a managing office with a manager and a manager assistant. Every semester, the academic director and his team organize a program with studies of philosophical, cultural, and social competence, a master program for philosophy of science and technology, and courses of teaching skills (PROLEHRE).

The mission of the Academy is: "Find and support creative potentials of TUM". In his paper, Ton Jörg underlined that the "potentiality of human beings" is a hidden "reality" which must become conscious. Potentiality leads to competence with crossover knowledge plus skills. The educational demands of complexity and transdisciplinarity are no longer only programmatic views, but they are realized: The program of interdisciplinary and intercultural studies for students is anchored in study and examination regulations. Further, we promote an elected circle of gifted students by means of an additional Masters degree in philosophy of science and technology. The quality of teaching should be supported with continuous evaluation and development of all learning modules. The top issue is human personality in the age of complexity and globalization. Personality needs motivation and creativity, responsibility, selforganization and self-performance, communication and cooperation, as well as qualities of leadership. Globalization comprises complexity of a global world, responsibility in a global world, world-wide interaction of economy, science, and politics, cultural 
communities and differences, risks and conflicts. Education in these two top issues enables cross-thinking and cross-acting with interdisciplinary thinking in complex systems (e.g., natural science, engineering, economics, humanities), deciding and acting in complex organizations (e.g., political, economic, scientific organizations), evaluating in complex cultures (e.g., ethical and religious values).

In more detail, there are six educational modules: (i) Complex systems and globalization, (ii) communication and information, (iii) ethics and responsibility, (iv) cultural competence, (v) values and change, and (vi) innovations and risks. The educational program, with courses of these modules, is supplemented by events of arts, and self-management. Courses in the six modules lead to key qualifications: With three courses in the same module, a student gets a certification. Three certifications deliver a key qualification for the special disciplines in the faculties (e.g., mathematics, natural sciences, engineering, medicine). Interdisciplinary key qualifications supplement disciplinary studies. We distinguish basic skills of methodic competence and self competence and orientation skills in economic, political, cultural, and ecological systems. Enabling skills of formal and operational knowledge are trained in the special studies of faculties and departments. Educational forms must be chosen according to the complexity of the human mind with workshops, series of lectures, blended learning units, summer schools, and tutorials.

Every semester, we offer a program with courses, workshops, and events. Typical titles of courses are, e.g., "Randomness, Risks, and Innovations," "Management of Complex Organizations," "Emotional Intelligence," "Communication, Information, and Media," "Cultural Competence." Workshops discuss issues of philosophy of science, economy, and psychology (e.g., "Neural Networks and Human Mind," "Tacit Knowledge and Creative Skills," "Deciding with Bounded Rationality"). According to their complex embodied mind, human beings are bodily nonlinear beings with emotions, imagination, and feeling. Thus, we also offer guided tours with memorials and media, mobility and technology in architecture, talks in the Pinakothek of Modern Arts, and courses at the Munich High School of Music. Every semester, there is a popular lecture to the broader audience of Munich, organized by the Carl von LindeAcademy. Titles of these lecture concern hot topics at the boundary of science, technology, economy, culture, and politics.

The mission of PROLEHRE means supporting the academic teaching at TUM to give students the best possible teaching. PROLEHRE is responsible for assuring and improving teaching quality, supporting teachers to develop and professionalize their individual teaching style, voluntary course and coaching offers with state-wide accepted certificates. Typical activities include training by means of lectures, individual coaching of lecturers, evaluation of teaching quality, developing and providing didactic advice, supporting innovative teaching pilot programs, consulting academic staff in teaching matters, and maintaining a dialogue on teaching culture. PROLEHRE offers courses on (i) interdisciplinary methodology of academic teaching, (ii) rhetoric and communication, (iii) media and e-learning, (iv) teaching and learning in a cross-cultural context, and (v) group-working techniques. 
The new media play an immense role in global education in complexity. In the knowledge society and knowledge-based economy, knowledge and skills of citizens are becoming increasingly important. Under this perspective, a new paradigm of personalized "on-demand" learning emerges, where the "anyone, anytime, anywhere" delivery of education and training is adapted to specific requirements and preferences of each individual citizen within different e-learning and e-working settings. When organizations (e.g., firms, universities, research laboratories, suppliers, and customers) become allies in partnership, a new interacting platform for learning is added: the interorganizational one. When organizations begin to adapt to larger networks, platforms for learning multiply. Virtual organizations are systems of networking partners who coordinate their activities through shared missions, visions, values, projects, and products.

In the age of complexity and globalization, the Carl von Linde-Academy is a center of interdisciplinary and intercultural education embedded in the Technical University of Munich (TUM) as global player of research and innovation. As director of the Carl von Linde-Academy, I have the opportunity to apply and to realize the concepts of complexity research in the field of university education. Ton Jörg's programmatic view enlarges the field of applications to the whole educational system in a complex world. I am deeply convinced that these ideas will become inevitable in the long run.

\title{
Literature
}

Mainzer, K. 2008. "The Emergence of Mind and Brain: An Evolutionary, Computational, and Philosophical Approach." In Progress in brain research 168. Models of brain and mind. Physical, computational and psychological approaches, edited by R Banerjee \& B.K. Chakrabarti , Amsterdam: Elsevier.

Mainzer, K. 2007. Thinking in complexity. The computational dynamics of matter, mind, and mankind. 5th enlarged edition. New York: Springer.

Mainzer, K. 2005. Symmetry and complexity. The spirit and beauty of nonlinear science. Singapore: World Scientific.

\begin{abstract}
About the Author
Klaus Mainzer is Director of the Carl von Linde-Academy, and Chair for Philosophy and Technology at the Institute of Advanced Study at the Technical University of Munich. Since 1996 he has been President of the German Society of Complex Systems and Nonlinear Dynamics. He is author or coauthor of over two dozen books, in German or English, on mathematics, philosophy, physics, the history of science, artificial intelligence, and communication technology. Many of his books are translated into other languages. His book Thinking in Complexity is now in its 5th (enlarged) edition.
\end{abstract}

(c) Copyright 2009. The author, KLAUS MAINZER, assigns to the University of Alberta and other educational and non-profit institutions a non-exclusive license to use this document for personal use and in courses of instruction provided that the article is used in full and this copyright statement is reproduced. The author also grants a non-exclusive license to the University of Alberta to publish this document in full on the World Wide Web, and for the document to be published on mirrors on the World Wide Web. Any other usage is prohibited without the express permission of the authors. 